\title{
Role conflict and ambivalence in the aged-parent-adult-child relationship
}

Role conflict and ambivalence

\author{
Xinjia Yu and Chunyan Miao
}

Joint NTU-UBC Research Centre of Excellence in Active Living for the Elderly (LILY) Nanyang Technological University, Singapore, Singapore

Cyril Leung

Department of Electrical and Computer Engineering, The University of British Columbia, Vancouver, Canada, and

\section{Charles Thomas Salmon}

Wee Kim Wee School of Communication and Information, Nanyang Technological University, Singapore, Singapore

\begin{abstract}
Purpose - The parent-child relationship is important to the solidarity of families and the emotional well-being of family members. Since people are more dependent on their close social relationships as they age, understanding the quality of relationships between aged parents and their adult children is a critical topic. Previous research shows that this relationship is complicated with both kinship and ambivalence. However, there is little research on the causes of this complexity. This paper proposes a role model to explain this complexity by studying the leadership transition within a family as the child grows.
\end{abstract}

Design/methodology/approach - In this paper, we proposed a novel perception to understand this transition process and explain related problems based on the analysis of the leader-follower relationship between the parents and their children.

Findings - When a child is born, his/her parents become the leader of this family because of their abilities, responsibilities and the requirements of the infant. This leader-follower role structure will last a long time in this family. Decades later, when the parents become old and the child grows up, the intergenerational contracts within the family and the requirement of each members change. This transition weakens the foundation of the traditional leader-follower role structure within the family. If either the parent or the child does not want to accept their new roles, both of them will suffer and struggle in this relationship. This role conflict will cause ambivalence in the relationship between aged parents and their adult children.

(C) Xinjia Yu, Chunyan Miao, Cyril Leung and Charles Thomas Salmon. Published in the International Journal of Crowd Science. Published by Emerald Publishing Limited. This article is published under the Creative Commons Attribution (CC BY 4.0) licence. Anyone may reproduce, distribute, translate and create derivative works of this article (for both commercial and non-commercial purposes), subject to full attribution to the original publication and authors. The full terms of this licence may be seen at http://creativecommons.org/licences/by/4.0/legalcode

This research is supported by the Interdisciplinary Graduate School, Nanyang Technological University, Singapore; and the National Research Foundation, Prime Minister's Office, Singapore, under its IDM Futures Funding Initiative.

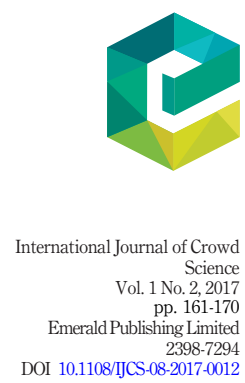

Received 11 August 2017 Revised 4 September 2017 Accepted 4 September 2017

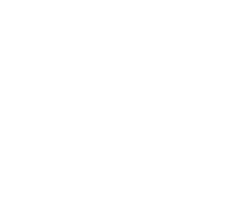


IJCS

1,2

Originality/value - Based on the quantitative study model provided in this paper, we can moderate the relationships between aged parents and their adult children. This effort is meaningful in enhancing the quality of life and emotional wellbeing for senior citizens.

Keywords Role, ambivalence, inter-generation relationship, parent-child

Paper type Research paper

\section{2}

\section{Introduction}

The parent-child relationship is the first and one of the most long-lasting relationships in an individual's social life. Facing the population ageing problem, it is increasingly important to understand this relationship, especially between aged parents and their adult children. According to the Socioemotional Selectivity theory, as the perception of future remaining time becomes limited, the elderly tend to rely more on the familiar persons around them instead of building new social partners (Fung and Carstensen, 2004). The quality of parentchild relationship is crucial to senior citizens' emotional well-being.

In this paper, we focus on the traditional families consisting of at least one biological parent and adult children. Many previous studies pointed out that the inter-generational relationship between aged parents and their adult children is complicated. On one hand, the children and their parents are close and inter-dependent. On the other hand, there are always tensions and conflicts between them. With the children's transition into adulthood, the family members' roles and the role structure of the family also change. If the family members continue to extend their previous interaction patterns, then they would face conflicts (Aquilino, 1997). Why are some aged parents angry about their children's efforts to take care of them? Why do some adult children feel hard to keep in touch with their parents? Does the transition based on life course affect the parent-child relationship? To answer these questions, this paper proposes a role conflict model based on the quantitative family role conflict and ambivalence testing scale.

According to the role theory, a role is a symbol for an individual in a society to communicate with others. Roles reflect norms, attitudes, contextual demands, negotiation and the evolving considerations of situations which are all understood by the members of the society (Heiss, 1981). The understanding of his/her role can affect the individual's behavioral pattern (Gordon and Gordon, 1982). This effect happens through the interaction and compromise among the role demands of the individual and the role expectation from the community which contains the individual. During this interaction, a temporarily balanced and stable role structure within the organization is formed. The imbalance of this structure will result in tensions on both individuals and the relationship among members of the organization.

A family is a small community. When a child is born, the parents become leaders in this community naturally for their abilities and responsibilities. During this process, the original role structure and the communication patterns within the family members are formed. A balanced role structure can not only benefit the solidarity of the family but also support the development of its members. However, with the growth of the children and ageing of the parents, their abilities and responsibilities change gradually. This trend results in the imbalance of the family role structure.

\section{Related work}

Previous research has unveiled the conflict between aged parents and their adult children caused by their status change. The theory of ambivalence is one of the most popular and systematic theories in this area. Ambivalence describes the mixed feelings of both positive 
and negative emotions toward the same relational objects (Freud, 1913). This theory was introduced by sociologists to study the relationship within family members recently (Luescher and Pillemer, 1998; Connidis and McMullin, 2002a). Quantitative studies based on the ambivalence theory were held to understand the coexistence of kinship and conflict between aged parents and their adult children. The ambivalence is shown to be negatively correlated to psychological health, life satisfaction and well-being of the senior population (Pillemer and Suitor, 2002; Bengtson et al., 2002; Lowenstein, 2007).

Relationships change as we age and result in shifts in power and dependency within a

Role conflict and ambivalence

163 family. This change and unbalance lead to ambivalence in perceptions among the family members (Willson et al., 2003). Luescher and Pillemer defined these changes as status transitions (Luescher and Pillemer, 1998). According to their research, these kind of transitions result in ambivalence in the parent-child relationship because they change the power contrast and dependency in the family. Walker studied the relationship between aged mothers and their adult daughters (Walker, 1994).

The bond between them may turn into a complex bilateral struggle of dependency and autonomy. Providing care to a parent increased ambivalence between the care-provider child and the care-recipient parent (Lowenstein, 2007). Previous empirical studies have demonstrated that the new power and dependency balance affected the relationships and the role structures in a family. This change expressed as the adult children provide support to their aged parents instead of receiving support when they were young. The provision of support includes financial support, caregiving during illness, information and advice, emotional support, decision-making support, etc. (Lendon et al., 2014).

Role conflict has been studied as a reason which causes tensions in parent-child relationship (Freud, 1913; Connidis and McMullin, 2002a; Lowenstein, 2007). In these studies, when a family member holds two or more roles, he/she may suffer from conflicting demands and expectations. For example, if a lady is living in a multi-generation family, she needs to play the role as both her mother's daughter and her children's mother. When she is facing a decision-making scenario to balance her work and family, her mother may expect her to chase personal achievement while her children may expect her to spend more time with the family. She will experience role conflict and inter-generational ambivalence in this situation. The key concepts of role theory include expectation, demand and ability, and the interactions among these factors. However, a majority of these studies define role based on the natural identity of an individual (e.g. as a daughter or a mother). However, in the role theory, sometimes we define role as a set of characteristic behaviors. It can be separated from the individual's social position (Biddle, 1979; Burt, 1982). In the previous scenario, the roles of "daughter" and "mother" are generated from the individual's social positions. Besides this perception, we can understand the roles within this family in another way by analyzing the functions of each individual family member. For example, who is the leader of the family? How is the leadership run? In this definition, one individual's role is not stable but transits based on the ability contrast among the members, his/her self-demand and the expectations from the other family members. This method is borrowed from the business management domain.

Detailed factors in role theory like expectation, demand and ability have been studied separately in previous parent-child relationship research. The aged parents' expectations toward their children to provide support are widely studied. Whitbeck, Hoyt and Huck found that when the aging parents expect care from their children, the expectations of both the parent and their children changed (Whitbeck et al., 1994). The negative affect of contraction between expectation and ability in family relationships is widely studied. Some researchers posited that providing support to their aged parents is the major reason of 
IJCS

1,2

inter-generational ambivalence (Aronson, 1992). However, some other empirical studies reported contrasting results. According to their studies, providing support and care to their parents is an expression of care and love, which positively influences the parent-child relationship (DeVault, 1991). There is little research on the reasons behind these contradicting findings.

Furthermore, though there are many empirical studies on ambivalence of the parentchild relationship, they mostly focused on separating variables and correlations. There is no study providing theoretical explanations to combine the variables to provide a systematic explanation about the reasons behind these phenomena. In this paper, we propose the role conflict model to address these issues.

\section{Role conflict model in parent-child relationship}

\subsection{Preliminaries}

Role theory uses the item of role to describe and analyze individuals' behaviors in social interactions. Role is a basis for individuals in a society to communicate with each other. Roles reflect norms, attitudes, contextual demands, negotiation and the evolving consideration of situation which are commonly understood by all members of a society. The understanding of one's role can affect an individual's behavioral pattern and relationships with others. This effect happens through the interactions and compromises among the role requirements on an individual and the role expectations from the society or organization to which the individual belongs.

A role contains a set of responsibilities, requirements and attitudes to others. In the leader-follower role structure in a family, the role of a leader is to take the following responsibilities:

- to provide support to the family members. Such support includes financial support, caregiving, information and advice, emotional support, etc. (Walker, 1994);

- to set clear goals of the family. A leader in a family has the responsibility to make major decisions about the development of the family and members. All the followers can depend on him/her when they are facing life choices; and

- to balance the needs of family members. A leader needs to understand not only the major needs of each family member but also the priority of them. They have the responsibility to distribute the family resources to maximize the benefits of the family.

In an inter-generational family, people tend to assign the leader role to the parents. However, as an individual's ability decreases with age and other reasons, the parents may face difficulty in leading their adult children. To explain this conflict and solve this problem, we propose a role conflict model.

\subsection{The role conflict model}

According to the role theory, the common beliefs and understanding of the members' roles can lead to a feeling of comfort and solidarity in the group. Otherwise, when the roles which the group would like the members to take conflict with the members' role expectations, the organization would face disruptions. To build positive relationships within an organization requires coherent social interactions based on roles. Roles are generated from the individual's role requirement about him/herself, and the role expectation toward this individual from the organization during the interactions. 
The integration of role requirements of an individual in an organization can be abstracted as the role he/she would like to play in the organization. It is generated by an individual's ability and self-concept. The former determines the limit of the individual's role. In other words, it means "what the individual can do". The latter reflects "what the individual wants to do". It is whether the family member is willing to be a leader or a follower. The intersection of these two factors is an individual's role requirement in his/her family. For example, when a working man lives with his aged parents, he is more powerful to provide financial support and care to the family than his parents. Meanwhile, he is glad to take care of his parents and make decisions for the families. In this situation, his role in his family shall be the leader. If his ability and self-concept do not match, then he will suffer from the intra-role conflict. In this case, if he wants to take care of his family but has no income to support the family spending, then he will be teared by the conflict and will hardly find a balance point to interact with his parents. This is the first level of the role conflict model: intra-role conflict which is caused by the conflict between individuals' ability and self-concept.

The other level of role conflict happens between the individual's role requirement and the role expectation toward him/her from his/her family. According to role theory, the organization has expectations on an individual's behaviors and attitudes. These expectations coalesce into the role which the organization would like a member to take up.

In the former scenario, the role expectation on the son is what role his parents would like him to play. If his parents accept his role as the leader which matches his own role requirements, the parent-child relation will be solidary and positive. Both parties can enjoy a harmonious family life. On the contrary, if his parents want him to obey the parental leadership as making decisions under the parents' guide, the man will suffer from a role conflict on an organizational level.

Besides these two levels, there is a third type of role conflict which comes from different expectations held by different organization members. For example, a mother may like the son to take care of the family, whereas the father cannot give up his leadership. In this situation, the son will suffer from role conflict caused by the contrary expectations.

Role conflict model defines an individual's role requirements based on his/her ability and self-concept. Meanwhile, the role of the focal individual is also affected by the role expectations toward him/her from the family. Figure 1 describes the logical framework of role conflict model. Role conflicts may happen on multiple levels. All of the conflicts may lead to ambivalence of the parent-child relationship and negative feelings.

The second level role conflict between the role requirement of the focal individual and the role expectation is the most complex. Furthermore, this type of role conflict can be invisible. The family members may discover the tensions in their relationship but can hardly articulate the reason because the role conflict may be covered by a boon tendency. In previous research, adult children reported higher level of tensions in the parent-child relationship than their parents (Clarke et al., 1999). The major reason of this phenomenon is that parents consider their expectation on their children as an effort to establish a closer relationship, whereas the children do not (Birditt et al., 2009). For example, parents tend to provide unsolicited advices, such as dress code, to their children. They believe the advices can benefit their children and promote their relationship. Actually, the adult children consider these unsolicited advices as overloaded requirements which result into relationship
Role conflict and ambivalence 
IJCS

1,2

166

Figure 1.

The framework of the role conflict model

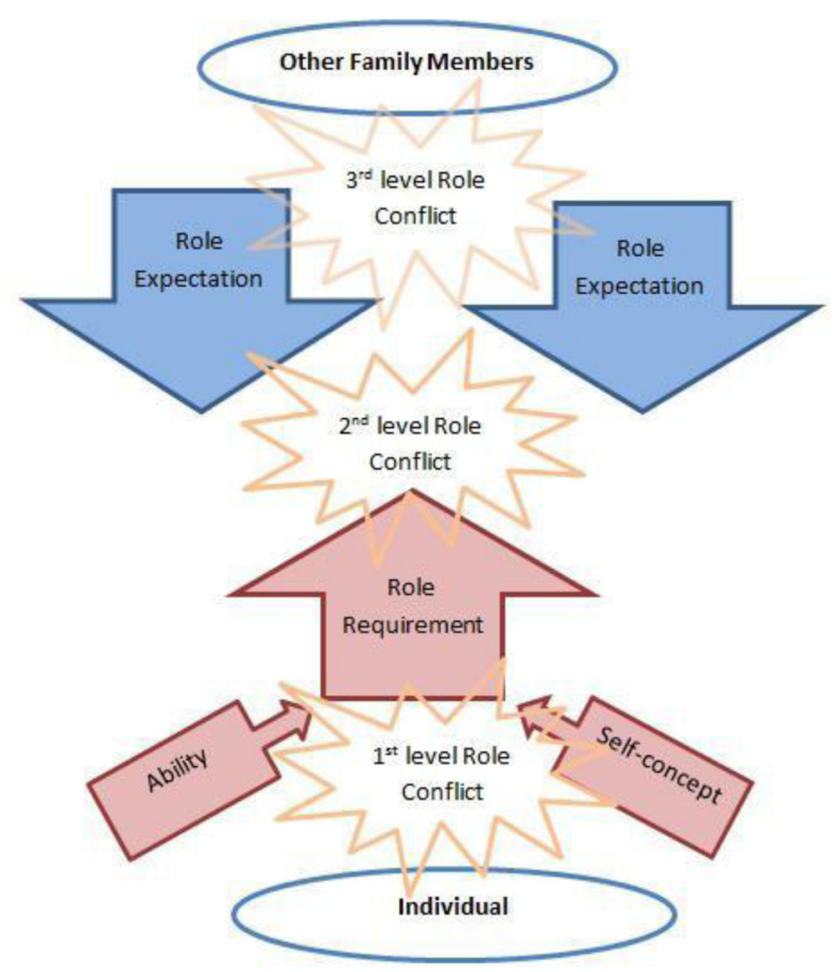

tensions. To address this problem, we proposed a scale to examine this type of role conflict and ambivalence within a family.

\section{The family role conflict and ambivalence testing scale}

This scale is developed to test the following correlations:

- The correlation between an individual's role conflict perception and the match between role requirement and role expectation.

- The correlation between an individual's role conflict perception and the ambivalence in his/her parent-child relationship.

To achieve these goals, the testing scale, as shown in Table I, includes questions on the following topics:

- Role requirement of the individual. As the ability of a participant can be derived from profile information, such as educational level, income, health status, mirage status, etc. the questionnaire will include only the questions toward self-concept.

- Role expectation of the family members toward the focal member.

- Practical role played by the focal individual in the family.

- The individual's perception of ambivalence within his/her parent-child relationship. 


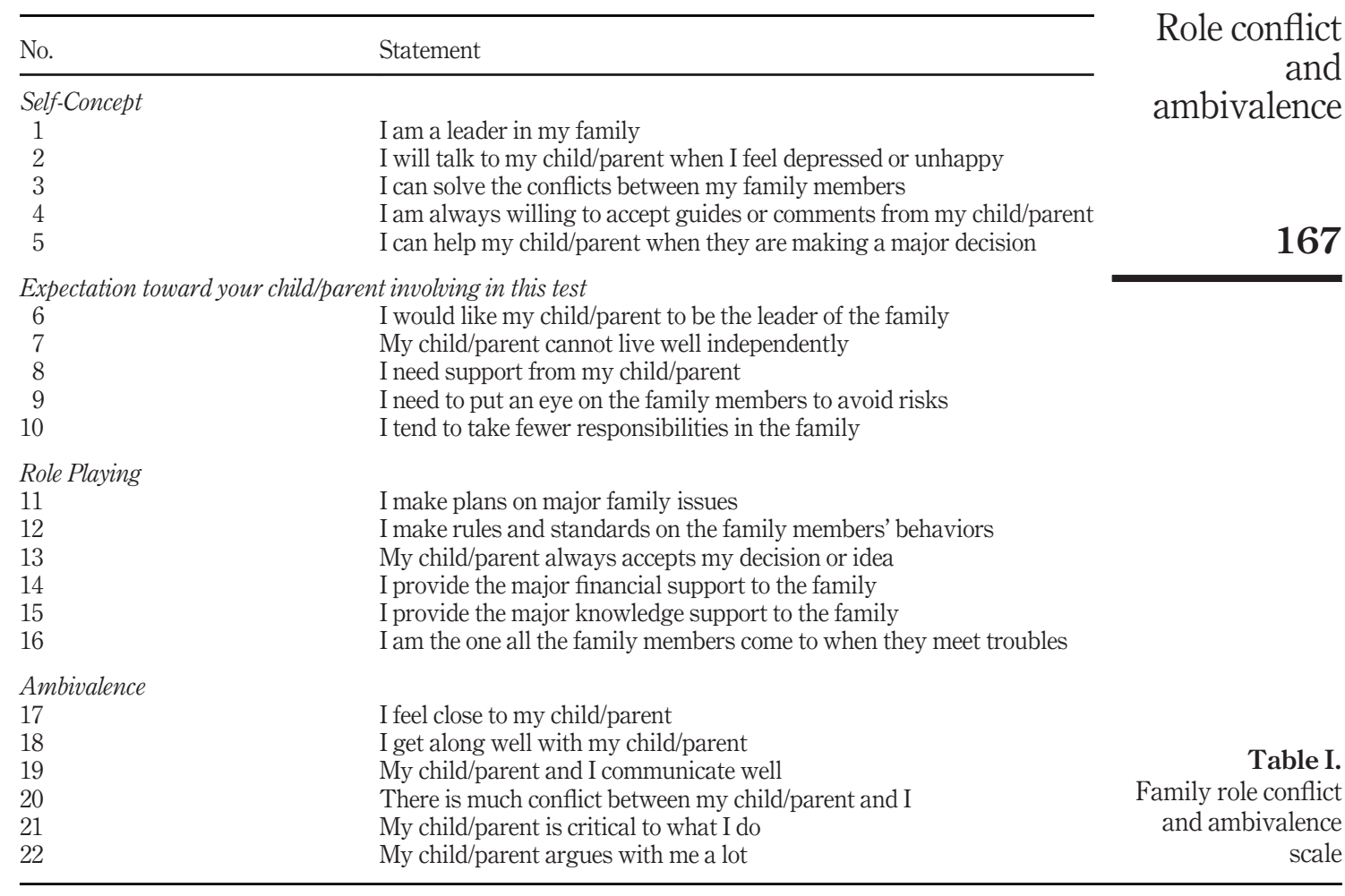

The questions related to role conflict are developed based on Implementation Leadership Scale (ILS) (Aarons et al., 2014) and Parent-Child Relations Dimension Scale (Aquilino, 1997). For the ambivalence exam, we chose the widely used indirect ambivalence measure (Bengtson et al., 2002; Clarke et al., 1999; Lendon et al., 2014; Thompson et al., 1995). Each question is displayed as a statement. The participants need to answer choosing from a five-point scale from 0 (strongly disagree) to 4 (strongly agree).

The child and his/her parent(s) will be required to answer the questions separately. Their answers will be compared to test their expectations toward each other. For the section on "Self-Concept", the odd numbered questions (1, 3 and 5) concerns leadership tendency. The even numbered questions (2 and 4 ) are related to the self-concept as a follower. By using the limit score 4 to subtract these scores, we can obtain the adjusted scores. Summing up the adjusted with the scores of the odd numbered questions, the final score of self-concept is generated. A higher score reflects a stronger wish by a participant to be the leader in the family. The score under "expectation toward your child/parent involving in this test" is calculated following the same method. The questions under "Role played" are designed to test the participant's real role in practical family life. The summary of the scores is positively related to the leader role.

In a harmonious role-playing situation, the participant's self-concept should not only match the role expectations from his/her family members but also match the role he/she is 
playing in the family. Otherwise, the participant is experiencing role conflict according to our definition. Our hypothesis is that the intensity of role conflict could be positively correlated to his/her perception of parent-child relation ambivalence.

\section{Conclusions and future work}

As time passes, children transit to adults and parents grow old. This transition brings inevitable changes in the parent-child relationship. Both parties feel complexity between the extension of previous interaction pattern and the conflict caused by new power contrast. In this paper, we proposed a novel perception to understand this transition process and explain related problems based on the analysis of the leader-follower relationship between the parents and their children. Some parents experience negative affect from their children's support. Meanwhile, some others accept the same situation well and enjoy the relation. Why this paradox exists widely in both research results and real life is a research question worth exploring. According to our proposed role conflict theory, the key to answering this question is neither based on behaviors nor personal characteristics, but based on the role structure of the family. If the child has ability and would like to provide support to his/her parent, then he/she will request to be the leader of the family. In one case, his/her parent expects him/her to be the leader. The focal individual's role requirement matches the role expectation from his/her family. He/she will enjoy the harmony of role playing as a family leader in this case. The parent-child relation will show less tension and ambivalence. In the other case, if the parents do not want to give up their previous leadership by accepting the support from their children, the role conflict happens. The parent-child relation between will show an ambivalence tendency. To validate this model, we developed the Family Role Conflict and Ambivalence Scale to test the role conflict of family members and ambivalence in the parent-child relation.

In future study, we will recruit participants to undertake the Family Role Conflict and Ambivalence Scale test to examine the explanation power of the role conflict model. Based on the quantitative study model provided in this paper, we can moderate the relationships between aged parents and their adult children. This effort is meaningful in enhancing the quality of life and emotional well-being for senior citizens.

\section{References}

Aarons, G.A., Ehrhart, M.G. and Farahnak, L.R. (2014), The Implementation Leadership Scale (ILS): Development of a Brief Measure of Unit Level Implementation Leadership, Implementation Science.

Aquilino, W.S. (1997), "From adolescent to young adult: a prospective study of parent-child relations during the transition to adulthood", Journal of Marriage and Family, Vol. 59 No. 3, pp. 670-686.

Aronson, J. (1992), “Women's sense of responsibility for the care of old people: "but who else is going to do it?", Gender and Society, Vol. 6 No. 1, pp. 8-29.

Bengtson, V.L., Giarrusso, R., Mabry, J.B. and Silverstein, M. (2002), "Solidarity, conflict, and ambivalence: complementary or competing perspectives on intergenerational relationships?", Journal of Marriage and Family, Vol. 64 No. 3, pp. 568-576.

Biddle, B.J. (1979), Role Theory: Expectations, Identities, and Behaviors, Academic, New York, NY.

Birditt, K.S., Miller, L.M., Fingerman, K.L. and Lefkowitz, E.S. (2009), "Tensions in the parent and adult child relationship: links to solidarity and ambivalence", Psychology and Aging, Vol. 24 No. 2, pp. 287-295.

Burt, R.S. (1982), Toward a Structural Theory of Action: Network Models of Social Structure, Perception, and Action, Academic, New York, NY. 
Clarke, E., Preston, M., Raksin, J. and Bengtson, V.L. (1999), “Types of conflict and tensions between older parents and adult children", The Gerontologist, Vol. 39 No. 3, pp. 261-270.

Connidis, I.A. and McMullin, J.A. (2002a), "Sociological ambivalence and family ties: a critical perspective", Journal of Marriage and Family, Vol. 64 No. 3, pp. 558-567.

DeVault, M.L. (1991), Feeding the Family, University Press of Chicago, Chicago.

Freud, S. (1913), Totem and Taboo: Some Points of Agreement between the Mental Lives of Savages and Neurotics, in Brill, A.A., Trans., New Republic, New York, NY.

Fung, H.H. and Carstensen, L.L. (2004), "Motivational changes in response to blocked goals and foreshortened time: testing alternatives to socioemotional selectivity theory", Psychology and Aging, Vol. 19 No. 1, pp. 68-78.

Gordon, C. and Gordon, P. (1982), "Changing roles, goals, and self-conceptions: process and results in a program for women's employment”, Personality, Roles, and Social Behavior, in Ickes W. and Knowles E.S. (Eds), Springer, New York, NY, pp. 243-283.

Heiss, J. (1981), "Social roles", Social Psychology: Sociological Perspectives, in Rosenberg, M. and Turner, R.H. (Eds), Transaction Publishers, New York City, NY, p. 95.

Lendon, J.P., Silverstein, M. and Giarrusso, R. (2014), "Ambivalence in older parent-adult child repathionships: mixed feelings, mixed measures", Journal of Marriage and the Family, Vol. 76 No. 2, pp. 272-284.

Lowenstein, A. (2007), "Solidarity-conflict and ambivalence: testing two conceptual frameworks and their impact on quality of life for older family members", Journals of Gerontology Series B: Psychological Sciences and Social Sciences, Vol. 62, pp. 100-107.

Luescher, K. and Pillemer, K. (1998), "Intergenerational ambivalence: a new approach to the study of parent- child relations in later life", Journal of Marriage and the Family, Vol. 60 No. 2, pp. 413-425.

Pillemer, K. and Suitor, J.J. (2002), "Explaining mother's ambivalence toward their adult children", Journal of Marriage and Family, Vol. 64 No. 3, pp. 602-613.

Thompson, M.M., Zanna, M.P. and Griffin, D.W. (1995), "Let's not be indifferent about (attitudinal) ambivalence", in Petty, R.E. and Krosnick, J.A. (Eds), Attitude Strength: Antecedents and Consequences, Erlbaun, Hillsdale, NJ, Vol. 4, pp. 361-386.

Walker, A.J. (1994), "You can't be a woman in your mother's house: adult daughters and their mothers", in Sollie, D.L. and Leslie L.A. (Eds), Gender, Families and Close Relationships: Feminist Research Journeys, Sage, Newbury Park, CA, pp. 74-96.

Whitbeck, L., Hoyt, D.R. and Huck, S.M. (1994), "Early family relationships, intergenerational solidarity, and support provided to parents by their adult children", Journal of Gerontology: Social Sciences, Vol. 49 No. 2, pp. S85-S94.

Willson, A.E., Shuey, K.M. and Glen, H. (2003), "Ambivalence in the relationship of adult children to aging parents and in-law", Journal of Marriage and Family, Vol. 65 No. 4, pp. 1055-1072.

\section{About the authors}

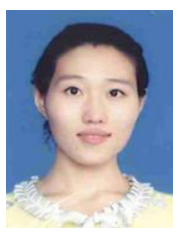

Xinjia $\mathrm{Yu}$ is a $\mathrm{PhD}$ candidate at Interdisciplinary Graduate School, The Joint NTUUBC Research Centre of Excellence in Active Living for the Elderly (LILY), Nanyang Technological University, Singapore. Xinjia Yu is the corresponding author and can be contacted at: alexandra-yu@hotmail.com 
IJCS

1,2

Chunyan Miao is a Professor, School of Computer Science and Engineering (SCSE), NTU, Director of The Joint NTU-UBC Research Centre of Excellence in Active Living for the Elderly (LILY).
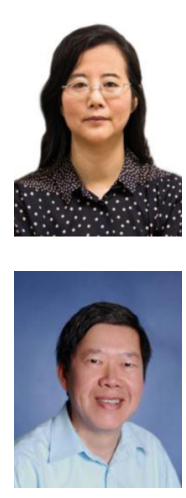

Cyril Leung is a Professor, Department of Electrical and Computer Engineering, UBC. Co-director of The Joint NTU-UBC Research Centre of Excellence in Active Living for the Elderly (LILY).

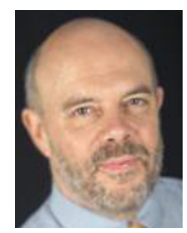

Charles Thomas Salmon is the Chair at Wee Kim Wee School of Communication and Information, Nanyang Technological University, Singapore.

For instructions on how to order reprints of this article, please visit our website: www.emeraldgrouppublishing.com/licensing/reprints.htm Or contact us for further details: permissions@emeraldinsight.com 